\title{
Personal safety when visiting patients in the community
}

\author{
Jean Galloway
}

Violence towards psychiatrists has been recognised as an occupational hazard for many years. With the development of community care it is increasingly likely to be encountered outside the hospital. To maximise personal safety in the community, psychiatrists need to be working in trusts in which an infrastructure to establish and maintain safety standards is in place.

This paper reviews the incidence and definition of violence and looks at current safety legislation and national guidance to UK trusts on the policies and procedures that should be developed. A method for implementing these recommendations by mental health directorates is suggested. Ways in which psychiatrists can practice safely when visiting the community are examined and the procedure to be followed after a violent incident is reviewed.

\section{Incidence of violence}

Over the past 30 years the number of reported violent incidents to health service employees has increased. This is likely to be owing to an increase in the absolute number of incidents as well as a reduction in tolerance of violence (Wykes, 1994). Violence is now the third largest cause of injuries in the National Health Service (Health and Safety Executive, 1997), after falls and needle accidents. Staff working in psychiatry and learning disability are particularly at risk (Health Services Advisory Committee, 1987). To keep this in perspective, however, we should note that the vast majority of those with mental illness or learning disability present no increased danger to others (Reed, 1997).

The reported incidence of assaults on psychiatrists varies. Davies (2001) reported that $17 \%$ of psychiatrists had been assaulted in the previous year. The Health Services Advisory Committee survey (1987) found that $25 \%$ of junior psychiatrists had experienced violence in the previous year. Kidd \& Stark (1992) stated that 35\% of junior psychiatrists had been assaulted at work and O'Sullivan \& Meagher (1998) found the incidence as high as $38.8 \%$. A study looking at staff in community mental health teams (CMHTs) revealed that $10 \%$ had experienced an assault (Eastwood \& Pugh, 1998). Davies (2001) found that of all assaults, 16\% occurred during domiciliary visits. With regard to verbal abuse, the reported incidence ranged from 16\% (Health Services Advisory Committee, 1987) to $68.4 \%$ (Eastwood \& Pugh, 1998). For physical injury the range was from $2.9 \%$ for staff in CMHTs (Eastwood \& Pugh, 1998) to 12\% for junior psychiatrists (O'Sullivan \& Meagher, 1998).

Guthrie et al (1999) found violence to be the jobrelated stressor that psychiatrists most commonly identified as affecting them. Trainee psychiatrists also cited it as a reason for not choosing a career in general adult psychiatry.

\section{Definition of work-related violence}

Although the number of violent incidents has increased, they are still underreported. Kidd \& Stark

Jean Galloway is a consultant in adult psychiatry for East Cheshire NHS Trust (Macclesfield District General Hospital, Victoria Road, Macclesfield SK10 3BL, UK). She was previously consultant in community psychiatry and old age psychiatry for Stockport and the High Peak. In 1998 she chaired a working party developing safety standards for doctors in psychiatry for the North West Postgraduate Deanery, and she participated in the Royal College of Psychiatrists' Safety Video Working Party, which produced the Mind's Eye videotape. 
(1992) found that junior psychiatrists reported only $50 \%$ of assaults made on them. One of the reasons for this is that psychiatrists have varying thresholds for perceiving an incident as violent. The definition of work-related violence adopted by recent Department of Health publications includes abuse and threats, as well as assaults (Royal College of Nursing, 1998; Department of Health, 1999). The Royal College of Psychiatrists' Safety Video Working Party (2000) describes specific behaviours in its definition of violence. These include shouting, verbal threats, invasion of personal space, damage to nearby objects, unwanted physical contact, harassment, stalking or telephone calls.

Harassment refers to a series of unrelated, unwanted, annoying minor offences (Dunne \& Schipperheijn, 2000). Stalking refers to the wilful, malicious and repeated harassment and following of another person that threatens his/her safety (Meloy \& Gothard, 1995). The important message is that violent incidents are not just those that involve physical assault, but include other types of threat.

\section{Legislation}

\section{Health and safety legislation}

The responsibility for psychiatrists' safety lies with both psychiatrists and their employers. A trust is criminally liable under the Health and Safety at Work Act 1974 if it fails to ensure, within reasonable limits, the safety at work of its employees. Employees have a duty under the Act to take reasonable care of their health and safety and that of their colleagues. Employees must cooperate with employers in fulfilling their statutory obligations (National Association of Health Authorities in England and Wales, 1996/1997). So what are trusts' statutory obligations?

\section{Trusts' statutory obligations}

There is a requirement under the Health and Safety at Work Act for a written policy identifying areas of risk and safe procedures for dealing with them. An organisation must also provide a safe system of work, a safe working environment, safe premises, adequate training, instruction and information that allows employees to ensure they are safe at work.

\section{Communication and training}

Another requirement under the Act is that the trust's security policy and documented assessment of risks are communicated to all staff so that they can respond effectively when an incident occurs. Setting out a policy for members of staff is not considered enough. Education and training are also required (National Association of Health Authorities in England and Wales, 1996/1997).

\section{Employees' rights}

In situations where employees believe that trusts could be doing more to improve their safety, employees are protected under the Employment Rights Act 1996. Under this legislation, employees have the right not to be penalised by their employers for pointing out hazardous working conditions and taking action to protect themselves and others. This may include leaving the workplace and refusing to return if a serious or imminent danger persists (Incomes Data Services, 1995).

\section{National guidance}

Three documents have recently been published with the aim of reducing violence toward health and social service employees: Safer Working in the Community (Royal College of Nursing, 1998); the Campaign to Stop Violence against Staff Working in the NHS: The NHS Zero Tolerance Zone (Department of Health, 1999); and the National Task Force on Violence against Social Care Staff (Department of Health, 2000). Safer Working in the Community stresses that commitment from trust boards and the provision of resources are fundamental to the development of good prevention and preparation strategies. It also emphasises that working groups of staff from all levels of the organisation should have input into developing policies and guidelines. Box 1 lists the main policies that should be developed in line with health and safety legislation.

The Royal College of Psychiatrists has published a Council Report, Safety for Trainees in Psychiatry (Royal College of Psychiatrists, 1999a), a videotape, The Mind's Eye (Royal College of Psychiatrists' Safety Video Working Party, 2000) and a chapter on the safety of trainees in the inceptors' handbook (Royal College of Psychiatrists, 1999b). These standards include an induction course with safety and breakaway technique training, written policies and procedures, standards for interview rooms in psychiatric departments, accident and emergency departments and community facilities, appropriate equipment such as personal alarms and mobile telephones, and a written procedure for trainees to follow after a violent incident. For psychiatrists in training, the Postgraduate Dean and the Royal College of Psychiatrists have a responsibility to 
Box 1 Policies that trusts need to develop (adapted from Royal College of Nursing, 1998)

A statement of the trust's intent to protect staff from work-related violence

A definition of violence that includes non-physical violence

A statement of the trust's legal obligations

Specific responsibilities of management and staff

Provision for violence to be included within the normal health and safety risk assessments

Implementation of measures to reduce the risk from violence, encompassing normal working procedures and emergency action plans

Provision for training staff

A system for reporting and recording incidents of violence

Provision for post-trauma support

A commitment to develop clear working relationships with the local police and prosecution services in pursuing cases of violence against staff and support staff through the process of prosecution

Provision for checking that duties under the policy have been carried out

Inclusion of community working, encompassing travelling, lone working and home visits

Procedures for dealing with bullying and harassment

Time limits for reviewing the above policy documents

ensure that trainees are in posts with adequate safety standards and that these are monitored on approval visits. Trusts are at risk of losing training status if standards are not met.

\section{A directorate infrastructure for implementing safety standards}

The following is a suggested infrastructure that would ensure the implemntation of safety standards.

Each trust should have a safety policy and a manager responsible for trust health and safety.

\section{Directorate safety group}

It is recommended that each psychiatry directorate has a safety group, the remit of which would be to look at:

(a) how the trust's safety policy applies to psychiatry;

(b) safety risks specific to psychiatry;

(c) ensuring that the recommended safety standards are met;

(d) auditing safety standards.

It is advisable for the group to have a representative from the directorate management, the consultant group (preferably the college tutor, as safety is an important training issue), ward staff, the community staff, a representative from the accident and emergency department and a trust health and safety representative. This group may want to develop its own strategy for identifying safety shortfalls and implementing improvements.

\section{Policies and procedures}

The safety group should ensure the development of written policies and procedures for responding to alarms, making case notes available 24 hours a day, lone workers, minimum staffing standards for assessing potentially violent patients and procedures after a violent incident.

\section{Psychiatry and police liaison meetings}

Regular meetings between psychiatry and police liaison officers can enhance relationships with the police. They enable safety information to be exchanged and facilitate rapid and appropriate action in the future, should staff require assistance. The help needed might include obtaining information for risk assessment of patients, obtaining a police escort or pursuing a prosecution following an assault.

\section{Safety training}

A safety induction course is required for all psychiatrists commencing employment with the trust. This would usually be at the start of each 6-month senior house officer (SHO) training post but newly employed non-training grade 
psychiatrists, such as staff grade doctors and consultants, should be expected to attend. This should include information on local safety policies and procedures, personal awareness, risk assessment, relevant interview techniques, interview room standards, management of violent incidents, situations where containment takes precedence over assessment and the procedure after a violent incident. It is also advisable to include this information in the trainees' handbook.

\section{Clinical risk management training}

At induction, psychiatrists need guidance on the local procedure for documenting clinical risk of violence. Identification and assessment of risk should be a normal part of the practice of psychiatrists and the multi-disciplinary team. A number of rating scales for the prediction of violence have been developed in the USA, based on a combination of actuarial and clinical predictors. These include the Historical/Clinical/ Risk Management 20-item Scale (HCR-20; Webster et al, 1997) and the Psychopathy Checklist (Revised) (PCL-R; Hare, 1991). They are well reviewed by Dolan \& Doyle (2000) and may be used more widely in the future.

The process of assessing risk requires the collection of information from a wide range of sources, including relatives, social services, general practitioners (GPs), the probation service and the police. Information also needs to be collected about the patient's personal history, present and past mental state, past behaviour and social functioning. A judgement then is made about the severity and frequency of the risk. The team should document the risk in terms of:

(a) aspects of lifestyle, illness and social circumstances that have been associated with risk in the past;

(b) early warning signs;

(c) treatment strategies to reduce the severity and frequency of violence.

The need for regular reviews of the risk should be emphasised (Snowden, 1997).

\section{Breakaway techniques}

These are techniques to break away from a violent patient without harming him or her. They do not include control or restraint methods. Breakaway skills require practice, so all psychiatrists need to refresh these skills at regular intervals. Psychiatrists need to go on a breakaway course at the start of their training and then annually thereafter.

\section{Practising safely when visiting the community}

Community work involves seeing patients at home, in residential care settings, day centres, health centres and community clinics, and travelling between different sites. Most of the safety procedures and precautions that apply to working in a hospital psychiatric unit also apply in the community and are described below.

\section{General personal safety precautions}

\section{Personal information}

Psychiatrists are wise to take precautions to prevent personal information becoming available to patients. Information such as home address, telephone number, marital status and names of family members may be misused and facilitate harassment or stalking. In the unlikely event of needing to telephone a patient from your home address, dialling 141 first prevents the patient from subsequently dialling 1471 and acquiring your telephone number.

For the more determined patient, the Medical Directory is accessible in public libraries so it is advisable not to publish your home address or telephone number. The Electoral Register is another potential source of information. It is possible to be in the Electoral Register under a different name. This can, however, lead to problems in obtaining credit, as the Electoral Register is used to check credit rating. It is also possible to choose not to be in the version of the Electoral Register that is sent out to the public on request. However, all names will continue to be published in the register kept at the Town Hall, should anyone be motivated to view it.

\section{Equipment}

It is essential that psychiatrists working in the community have access to a mobile telephone or a radio so that help can be summoned. Programming the work base number into the telephone so that contact can be made by pressing one button is helpful. Personal alarms may also be useful, particularly if psychiatrists are unable to use their telephone but would like to attract the attention of people nearby. The alarm needs to be readily accessible, on a belt or waistband, and to have functioning batteries. 


\section{Box 2 Lone worker policy}

Identify a 'responsible person'

Give the responsible person access to the worker's details, including:

- make, model, colour and registration number of car

- mobile telephone number

- home telephone number

- names, addresses and telephone numbers of patients to be visited

- approximate times of visits

- agreed time for worker to make contact after last visit

If a worker fails to make contact:

1 Telephone the mobile phone

2 If no answer, telephone the home number

3 If not there, telephone the home numbers of patients visited, in reverse order

4 If not there, allow the agreed period to elapse after the expected contact time then inform the police of a suspicious incident

\section{Personal appearance}

Under normal circumstances it is recommended that psychiatrists dress smartly (Gledhill et al, 1997) because this maximises rapport with patients. In certain inner-city areas, however, where there is a high incidence of crime, doctors may be the target of attacks with the expectation of finding money or drugs. Dressing in a way that does not mark the psychiatrist out as being a doctor is advisable. Casual clothes may be less conspicuous than a suit. Flat shoes and loose clothes may facilitate rapid escape in an emergency.

Parking

In areas of high crime, parking as near to the destination as possible to minimise the risk of being attacked and to facilitate a quick escape is advisable. Obtaining the exact location of the address and the nearest parking areas from the GP or the referrer before the visit is helpful. A-Z maps do not give this degree of detail.

\section{Lone worker policy}

Before contemplating any community visits, it is important to be familiar with the trust's lone worker policy. This is a system for ensuring that a responsible person in the trust knows of your intended whereabouts and can raise the alarm if you fail to either return to the base or make contact at an appointed time. The responsible person could be a consultant's secretary under the supervision of a secretarial manager or a nursing manager. This responsibility may need to be passed on to an outof-hours service manager or a ward manager at the end of the normal working day. It is important that this policy is adhered to however safe the visits are expected to be. The details of this policy will vary from trust to trust. The essential components are shown in Box 2.

\section{Risk assessment}

Before agreeing to see any patient, it is important psychiatrists assess the risk of that patient being violent and ensure that they are not exposing themselves to danger. It has been shown that the best predictors of violence in those with mental disorder are the same as those for the rest of the population; they include previous violence, poor parenting and criminality within the family. People with schizophrenia and bipolar affective disorder may present an increased risk to others when they have active symptoms. This risk can be seriously increased if there is concurrent misuse of drugs or

Box 3 Risk factors for short-term prediction of violence

Demographic and personal history

Youth, male

A history of violence

Recent threats of violence

Belonging to a subculture where violence is prevalent

Clinical variables

Alcohol or other substance misuse

Symptoms of schizophrenia or mania, especially if:

- delusions of hallucinations are focused on an individual

- there is a specific preoccupation with violence

- there are delusions of control with a violent theme

- there is agitation, excitement, overt hostility or suspiciousness

- there is poor compliance with treatment

- there are antisocial, explosive or impulsive personality traits

Situational factors

Lack of social support

Immediate availability of a weapon 
alcohol. By definition, people with psychopathic disorder present an increased risk of violence (Reed, 1997). The risk factors for short-term prediction of violence are outlined in Box 3 (adapted from Royal College of Psychiatrists, 1998).

\section{Obtaining information before a home visit}

The accuracy of a risk assessment depends on the information obtained prior to the visit. For new referrals this assessment will be based on information given either in the referral letter or verbally and recorded by the psychiatrist or secretary. It is important that the referrer is asked about any history of violence and substance misuse as these are two risk factors for violence that may not relate to the presenting problem and therefore could be overlooked. Obtaining this information can be facilitated by having a standard form for domiciliary visit requests that includes the headings 'history of violence' and 'history of substance misuse'. If you suspect that there is a history of violent offences the police will confirm any reported incidents. Old psychiatric notes may be available even if the patient is a new referral.

For patients who are in the service but are not known to the psychiatrist being asked to visit, it is important to obtain the old notes. The procedure for accessing the notes may involve sending a taxi to another site for them. The notes may include a risk assessment, completed as part of the patient's care under the Care Programme Approach, identifying a risk of violence, its severity and frequency, the circumstances in which this risk may be increased and early warning signs (Snowden, 1997). There may also be a management plan that includes information about the precautions necessary when visiting the patient in the community.

\section{Home visits}

\section{How to decide the appropriate level of staff support for home visits}

A psychiatrist would not perform a home visit if the patient were armed with a weapon, had made a specific threat against the psychiatrist or had a recent history of violence. In these circumstances it would be appropriate to ask the police to arrest the patient and take him or her to a place of safety, preferably a police station, where the assessment could take place.

If a patient has had a relapse of psychosis and has other risk factors for violence (such as substance misuse, a history of past violence, persecutory delusions or delusions of passivity) or is hostile, agitated or suspicious, involving the police is recommended. Where it is anticipated that the patient will need to be admitted compulsorily, the police will be required.

The situation is less clear where the patient is not thought to be actively psychotic but other risk factors are present, for example a history of substance misuse, failure to comply with treatment or antisocial, explosive or impulsive personality traits. In these circumstances, visiting with at least one other person, preferably one whom the patient knows and gets on with, is wise, but decisions on further backup will depend on the level of knowledge and past rapport with the patient.

For low-risk patients, visiting alone is reasonable. However, it is advisable to take a professional colleague if there is reason to believe that the patient has had a relapse of psychosis or if the psychiatrist has perceived the individual as threatening in the past or if there are risks that he or she will make allegations of improper behaviour against the psychiatrist. In inner-city areas with a high crime rate or where a patient's relative has a history of aggressive behaviour, it is also wise to take a colleague.

\section{Evening visits}

Emergency visits in the evening are usually for assessment for compulsory admission under the Mental Health Act. There should therefore be at least a GP and a social worker present together with the police if conveyance to hospital or violence is expected to be a problem. Routine home visits often take place out of normal office hours. If a psychiatrist is running late with visits it is important to let the responsible person know this and to contact him or her when the visits have been completed.

\section{Precautions during visits}

When entering a patient's house, it is important to look for your escape route and memorise it. If the patient has a dog, it is a wise to ask for it to be kept in another room. Dogs can become vicious if they see their owners becoming upset. If at any stage during the interview you feel under threat, leave as quickly as possible. When conducting the interview the normal techniques for interviewing a patient anywhere apply. These are summarised in Box 4 .

In the unfortunate circumstance of being unable to leave, for example if the door is locked, or your escape route is blocked, then using de-escalation techniques is the only option. These are described in Box 5. 


\section{Box 4 Safe interviewing techniques}

Introduce yourself

Produce identification

Speak clearly without raising your voice Use the patient's appropriate title and name Allow plenty of personal space

Avoid prolonged eye contact, especially if the patient is experiencing a psychotic episode Avoid turning your back on the patient Persuade a standing patient to sit down Do not sit down if the patient remains standing Use an interpreter if appropriate Avoid note-taking if the patient is suspicious

\section{Community out-patient clinics}

Out-patient clinics in health centres or other community facilities can present risks. While standards of safety may be good in out-patient departments within psychiatric units, they are often lower in community facilities that are also used by specialities facing a lower level of risk. Nevertheless, if psychiatrists are using community facilities then it is the trust's responsibility to ensure that safety standards for a psychiatric interview room are met. These are summarised in Box 6 .

If psychiatrists find themselves expected to use substandard interview rooms, they should report the situation to the trust management. In the meantime, temporary safety precautions can be implemented:

- ensure someone is within earshot

- if the room is isolated and no other room is available, request a member of the clinic staff to be available outside the room

\section{Box 5 De-escalation techniques}

Try to summon help on your mobile telephone Maintain an adequate distance

Move towards the door and avoid corners

Explain your intentions to the patient and to any others present

Try to appear calm, self-controlled and coherent

Ensure that your non-verbal communications are non-threatening

Engage in conversation, acknowledge concerns and feelings

Ask for the facts about the problems and encourage reasoning

If a weapon is produced ask for it to be put down rather than handed over
Box 6 Safety standards recommended for a psychiatric interview room (adapted from Royal College of Psychiatrists, 1999a)

Located near other staff

Contains a functioning alarm with a protocol for responding

Exit is safe: door opens outwards, no key is needed to leave and exit is unobstructed

Observation panel in door or wall

Furniture appropriately situated, the psychiatrist sitting between the patient and the door

No potential weapons, e.g. paperweights

- use a personal alarm if no permanent alarm is installed and inform the clinic staff

- rearrange the furniture.

Avoid seeing high-risk patients in this setting without adequately trained staff members present.

\section{Procedure after a violent incident}

If a psychiatrist is injured or significantly distressed, he or she should seek immediate medical attention and take time off from duties and sick leave. If a psychiatrist is being harassed and/or stalked, he or she should report it to the trust and consider involving the police.

\section{Psychiatric records}

All types of violent incident, whether they be harassment, threats or assaults, should be recorded in the patient's notes. This highlights the risk to staff having contact with the patient in the future. It also provides evidence should the psychiatrist or patient pursue legal action.

\section{Violent-incident forms}

Each trust should have a system for reporting violent incidents. It is important that psychiatrists complete these forms as they allow the trust to audit them and correct any shortfalls in standards that may have contributed to the incident. Failure to report an incident may allow the same circumstances to arise again, placing a colleague at risk. Reasons why psychiatrists may not report incidents are listed in 
Box 7 Factors influencing the underreporting of violent incidents (adapted from Kidd \& Stark, 1992; Eastwood \& Pugh, 1998)

Failure to recognise that the incident fulfils the definition of a violent incident

The assumption that verbal abuse and threats are part of the job

The belief that the psychiatrist mishandled the incident and will be seen as professionally incompetent

To avoid the attention that reporting a distressing incident will bring

The belief that management will be unsupportive

The belief that reporting the incident will make no difference

Forms that are complex, numerous or inconveniently situated

Box 7. Training should be designed to look at these problems.

\section{Psychological support}

\section{Counselling}

If the psychiatrist was the only person involved in an incident, counselling sessions should be offered by the occupational health department, with the option of seeing a counsellor outside the trust. If the psychiatrist is reluctant then, at the very least, he or she should be encouraged to talk to a colleague about it. The fact that psychiatrists take what seem to be unreasonable risks may be due to such factors as heavy work load, unavailability of other staff members, time pressures or lack of training. These are all factors that can be addressed.

\section{Debriefing}

This should be arranged following an incident in which several people were involved. Although no systematic evaluation of the effectiveness of debriefing after a violent incident has occurred (Bisson \& Deahl, 1994) and it has not been shown to prevent future psychological distress (Raphael et al, 1995), the experience of workers in the field is that 'victims' are grateful for the opportunity to express feelings and achieve some understanding of what has happened (McIvor et al, 1997). They recommend that each trust has a trauma advisor, possibly from the occupational health department, who should be consulted by the senior clinical staff member in the area where the incident took place and arrange the debriefing session within 3 days. They recommend that staff, patients and bystanders involved in the incident should be encouraged to attend. Discussion should be about what happened, any trigger factors, individuals' role in the incident, how they feel now, how they may feel in the next few days and what can be done about it. They recommend that the session last about 2 hours and be run by appropriately trained staff who are not well known to the participants.

\section{Legal action}

Doctors need to consider whether to press charges against the perpetrator of an assault after discussing the case with a lawyer and medical defence society. Trusts are expected to support staff in dealing with the police and help them to apply for compensation through the Criminal Injuries Compensation Authority or NHS Injury Benefit Scheme.

\section{Conclusion}

With the development of community psychiatry, more psychiatrists are seeing patients in situations in which they are potentially vulnerable. If we are to attract more junior doctors to this understaffed speciality and maintain the morale of existing practitioners, then the hazards of the job must be minimised.

Violence in health care is topical and the national guidance on safety has never been more explicit. The responsibility now lies with trusts, in collaboration with psychiatrists and other professionals, to implement the guidance. This is an excellent opportunity to improve standards for future generations of psychiatrists.

\section{References}

Bisson, J. I. \& Deahl, M. P. (1994) Psychological debriefing and prevention of post-traumatic stress. More research needed. British Journal of Psychiatry, 165, 717-720.

Davies, S. (2001) Assaults and threats on psychiatrists. Psychiatric Bulletin, 25, 89-91.

Department of Health (1999) Campaign to Stop Violence against Staff Working in the NHS: NHS Zero Tolerance Zone. HSC 1999/226. London: Department of Health.

- (2000) National Task Force on Violence Against Social Care Staff. London: Department of Health.

Dolan, M. \& Doyle, M. (2000) Violence risk prediction: clinical and actuarial measures and the role of the Psychopathy Checklist. British Journal of Psychiatry, 177, 303-311.

Dunne, F. J. \& Schipperheijn, J. A. (2000) Stalking (obsessive pursuit). Hospital Medicine, 61, 31-32.

Eastwood, N. \& Pugh, R. (1998) Violence in the community: study of community mental health teams. Psychiatric Bulletin, 22, 531-533. 
Gledhill, J. A., Warner, J. P. \& King, M. (1997) Psychiatrists and their patients: views on forms of dress and address. British Journal of Psychiatry, 171, 228-232.

Guthrie, E., Tatton, T., Williams, E., et al (1999) Sources of stress, psychological distress and burnout in psychiatrists. Comparison of junior doctors, senior registrars and consultants. Psychiatric Bulletin, 23, 207-212.

Hare, R. D. (1991) Manual for the Hare Psychopathy Checklist - Revised. Toronto, Canada: Multi Health Systems.

Health Services Advisory Committee (1987) Violence to Staff in the Health Services. London: HMSO.

Health and Safety Executive (1997) Violence and Aggression to Staff in the Health Services, Guidance on Assessment and Management (2nd edn). Sudbury: HSE Books.

Incomes Data Services (1995) Employment protection health and safety cases. In IDS Brief 553, pp. 7-12. London: Incomes Data Services.

Kidd, B. \& Stark, C. R. (1992) Violence and junior doctors working in psychiatry. Psychiatric Bulletin, 16, 144-145.

McIvor, R. J., Canterbury, R. \& Gunn, J. (1997) Psychological care of staff following traumatic incidents at work. Psychiatric Bulletin, 21, 176-178.

Meloy, J. R. \& Gothard, S. (1995) Demographic and clinica comparison of obsessional followers and offenders with mental disorders. American Journal of Psychiatry, 156, 1244 1249

National Association of Health Authorities in England and Wales (1996/1997) NHS Handbook. NAHA, the National Association of Health Authorities. London: Macmillan Reference.

O'Sullivan, M. \& Meagher, D. (1998) Assaults on psychiatrists - a three year retrospective study. Irish Journal of Psychological Medicine, 15(2), 52-57.

Raphael, B., Meldrum, L. \& McFarlane, A. C. (1995) Does debriefing after psychological trauma work? Time for randomised controlled trials. BMJ, 310, 1479-1480.

Reed, J. (1997) Risk assessment and clinical risk management - the lessons from recent inquiries. British Journal of Psychiatry, 170 (suppl. 32), 4-7.

Royal College of Nursing (1998) Safer Working in the Community. A Guide for NHS Managers and Staff on Reducing the Risks from Violence and Aggression. London: Royal College of Nursing.

Royal College of Psychiatrists (1998). Management of Imminent Violence. Occasional Paper OP41. London: Royal College of Psychiatrists.

- (1999a) Safety for Trainees in Psychiatry. Report of the Collegiate Trainees' Committee Working Party on the Safety of Trainees. Council Report CR78. London: Royal College of Psychiatrists.

- (1999b) Safety of trainees. In Handbook for Inceptors and Trainees in Psychiatry, pp. 108-112. London: Royal College of Psychiatrists.

Royal College of Psychiatrists' Safety Video Working Party (2000) The Mind's Eye. London: Royal College of Psychiatrists.

Snowden, P. (1997) Practical aspects of clinical risk assessment and management. British Journal of Psychiatry, 170 (suppl. 32), 32-34

Webster, C. D., Douglas, K. S., Eaves, D., et al (1997). HCR 20 Assessing Risk of Violence (Version 2). Vancouver: Vancouver Mental Health Law and Policy Institute, Simon Fraser University.

Wykes, T. (1994) Violence and Health Care Workers. London: Chapman \& Hall.

\section{Multiple choice questions}

1. The following can be said about violence:

a it is the most common cause of injuries in the health service

b it should be considered part of the job

c the number of assaults in mental health trusts is above the average for all trusts

$\mathrm{d}$ it is the job-related stressor that psychiatrists most commonly identify

e it does not include stalking.

2. Breakaway techniques:

a are not essential for psychiatrists

$\mathrm{b}$ are another name for control and restraint techniques

c need to be practised

$\mathrm{d}$ can be maintained by a 5-yearly refresher course

e aim to injure the patient.

3. Lone worker policy:

a should be used only if the psychiatrist anticipates significant risk

$\mathrm{b}$ requires the nomination of a responsible person

c only applies out of normal office hours

$\mathrm{d}$ requires the psychiatrist to make contact after completing visits

e may involve calling the police.

4. The following factors are recognised as shortterm predictors of violence:

a alcohol intoxication

b dementia

c lack of compliance with drug treatment

d impulsive personality traits

e femalegender.

5. Following a violent incident:

a a violent-incident form should be completed

b debriefing sessions should occur within 1 month of the incident

c counselling should not be offered to victims unless requested

$\mathrm{d}$ if the perpetrator is a patient, legal action should not be considered

e violent-incident forms should be audited by the trust.

MCQ answers

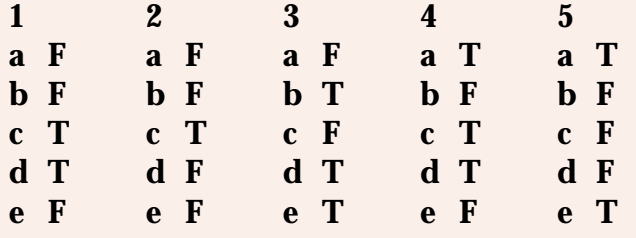

